\title{
Activation Level of JNK and Akt/ERK Signaling Pathways Determinates Extent of DNA Damage in the Liver of Diabetic Rats
}

\author{
Vesna Martinović ${ }^{1}$ \\ Ilijana Grigorov ${ }^{1}$ \\ Desanka Bogojević ${ }^{1}$ \\ Anja Petrović ${ }^{1}$ \\ Sofija Jovanović ${ }^{1}$ Mirka Ilić ${ }^{2}$ Svetlana Ivanović Matić
}

${ }^{1}$ Department of Molecular Biology, Institute for Biological Research, University of Belgrade, Belgrade;

${ }^{2}$ Clinical Center of Serbia, Belgrade, Serbia

\section{Key Words}

Rat Liver • Diabetes $•$ Oxidative Stress $\cdot$ DNA Damage $・$ Signaling Pathways

\begin{abstract}
Aims: Diabetes-related oxidative stress conditions lead to progressive tissue damage and disfunctionality. Mechanisms underlying liver pathophysiology during diabetes are not fully understood. The aim of this study was to find relationship between diabetes-related DNA damage in the rat liver and activities of prosurvival signaling pathways. Methods: Effect of diabetes was analyzed two (development stage) and eight weeks (stable diabetes) after single intraperitoneal injection of streptozotocin. Extent of DNA damage, analysed by comet assay, was corelated with oxidative status (plasma level of ROS, liver antioxidant capacity) and activity/abundance of kinases (Akt, p38, ERK1, JNK, JAK) and transcription factors NF- $\mathrm{B} B$ p65 and STAT3. Results: Significant DNA damage in development stage is accompanied by elevated plasma levels of $\mathrm{O}_{2}^{-}$and $\mathrm{H}_{2} \mathrm{O}_{2^{\prime}}$ decreased activities of CAT, MnSOD, and GST in the liver and increased activation of proapoptotic JNK signal pathway. Lower DNA damage in stable diabetes, is accompanied by elevated plasma level of $\mathrm{O}_{2}{ }_{2}$, restored antioxidative liver enzyme activity, decreased activation of JNK and increased activation of prosurvival Akt and ERK signal pathways. Conclusion: These findings indicate that level of DNA damage in diabetic liver depends on the extent of oxidative stress, antioxidant activity and balance between JNK and Akt/ERK signal pathways activation.
\end{abstract}




\section{Introduction}

Diabetes mellitus is a metabolic disease characterized by the elevated concentration of blood glucose and lipid abnormalities. Elevated glucose causes oxidative stress due to increased production of mitochondrial reactive oxygen species (ROS), non-enzymatic glycosylation of proteins and glucose autooxidation [1, 2]. Chronic exposure to high concentrations of glucose and fatty acids can cause damage to cells by different mechanisms but oxidative stress may be a common link in cell dysfunction [3-6].

ROS include various partially reduced metabolites of oxygen (e.g., super oxide anions $\left(\mathrm{O}_{2}^{-}\right)$, hydrogen peroxide $\left(\mathrm{H}_{2} \mathrm{O}_{2}\right)$, and hydroxyl radicals), all which elicit a broad spectrum of responses in cells. These responses depend upon the severity of the damage, which is further influenced by cell type, the magnitude of the dose and the duration of the exposure $[2,7]$. Typically, low doses of ROS, particularly $\mathrm{H}_{2} \mathrm{O}_{2}$, promote cell proliferation, while intermediate doses result in either temporary or permanent growth arrest. When present at high levels, ROS can cause severe damage to DNA, proteins and lipids which could lead to cell death via either apoptotic or necrotic mechanisms. A number of defense systems have evolved to combat the accumulation of ROS [8]. Tissues are equipped with several enzymatic antioxidant defense mechanisms, including super oxide dismutase (SOD), which converts $\mathrm{O}_{2}^{-}$into $\mathrm{H}_{2} \mathrm{O}_{2}$; catalase (CAT) and glutathione peroxidase (GPx) which decompose $\mathrm{H}_{2} \mathrm{O}_{2}$ into water [1]. However, ROS generation often exceeds the cell's antioxidant capacity, resulting in oxidative stress [1].

Coordination and balance between cell survival and cell death is crucial for normal development and homeostasis of organisms. Failing to control, this balance may contribute to a development of numerous diseases, including diabetes. In addition to the well-known cardiovascular, renal, and ophthalmologic complications caused by diabetes, liver-related complications occur commonly and are often unrecognized. Clearly there are tissues that are more susceptible to be damaged in diabetes (heart, kidney, and retina) and those that are more resistant (liver). Usually, this is associated with antioxidant capacity of the cells, but it seems that the situation is far more complex.

The importance of oxidative damage in the pathogenesis of diabetes has become increasingly apparent over the past years [9]. Many studies have investigated the role of ROS in hepatoma cells and in primary hepatocytes, although it is known that cell lines differ significantly from normal hepatocytes in many respects [10]. Since present in chronic diseases, like diabetes, non-transformed hepatocytes are exposed to various ROS, hence it is clinically significant to clarify the mode and the mechanism of hepatocyte functioning under these conditions.

Host survival depends upon the ability of cells and tissues to adapt/resist the stress or repair/remove damaged molecules or damaged cells. Numerous stress-response mechanisms have evolved for these purposes and they are rapidly activated in response to oxidative insults. Some of those mechanisms included activation of tumor necrosis faktor $\alpha$ (TNF $\alpha$ ) related signaling pathways in the cells as well as JAK/STAT signaling pathway [2,11]. Certain pathways are preferentially linked to enhanced survival while others are more frequently associated with cell death [12]. It seems that this effect largely reflects the balance between various intracellular stress signaling pathways that are activated in response to the oxidative insult. These pathways exert their phenotypic influences largely through the modulation of transcription factor activities that effect changes in the pattern of gene expression.

Streptozotocin (STZ) is widely used to induce insulin-dependent diabetes mellitus in experimental animals because of its toxic effects on islet beta cells $[13,14]$. The diabetogenic action of STZ is the direct result of irreversible damage to the pancreatic beta cells resulting in degranulation and loss of ability to secrete insulin. The aim of this work was to investigate the level of DNA damage and differences in hepatocyte's ability to run prosurvival signaling pathways during the development stage (two weeks) and stable diabetes (eight weeks) induced by STZ administration. Analysis of the signaling pathways during these stages, with 
emphasis on their activation and coordination, will help understand which of the signal pathways contribute to survival and protection of hepatocytes and which are crucial for pathogenesis and complications associated with liver damage during diabetes.

\section{Materials and Methods}

\section{Animals and treatment}

All animal procedures were approved by the Committee for the Ethical Care and Use of Laboratory Animals of the Institute for Biological Research, Belgrade and were in accordance with the Guide for the Care and Use of Laboratory Animals published by the US National Institutes of Health (NIH Publication No. 85/23, revised 1986). Male Wistar rats weighing approximately $220 \mathrm{~g}$ were used. Animals were housed three per cage at a constant temperature $\left(22 \pm 2^{\circ} \mathrm{C}\right)$, humidity $(50 \pm 5 \%)$ and $12 \mathrm{~h}$ dark/light intervals. Tap water and standard laboratory chow were available ad libitum. Diabetes was induced by a single intraperitoneal injection of STZ (60 mg/kg, Sigma, St. Louis, MO) that was dissolved in freshly prepared $0.01 \mathrm{~mol} / \mathrm{l}$ sodium citrate, $\mathrm{pH}$ 4.5. Blood samples for glucose monitoring were obtained from the tail tip using a hand-held glucometer (GlucoSure Plus, Apex Biotechnology Corp, Taiwan). Rats with a fasting blood glucose concentration greater than $20 \mathrm{mmol} / \mathrm{l}$ were considered as diabetic. In a single experimental cycle the following groups of animals were used: (i) a control group consisting of 20 rat that received saline (ml/ $\mathrm{kg}$ ); (ii) a group of 40 rats that were injected with STZ. Rats with induced diabetes were randomly divided in two groups ( 15 each) and killed by decapitation at $2^{\text {nd }}$ (the development stage of diabetes) and $8^{\text {th }}$ week after STZ administration (stable diabetes).

\section{Determination of TNF $\alpha$}

Serum concentration of rat TNF $\alpha$ was measured by the ELISA method according to the protocol provided by the manufacturer (Thermo Fisher Scientific, USA)

\section{Preparation of liver nuclear extracts}

Livers from control and diabetic rats were homogenized in buffer containing $2 \mathrm{M}$ sucrose, $10 \mathrm{mM}$ HEPES pH 7.6, $25 \mathrm{mM} \mathrm{KCl} 5 \mathrm{mM} \mathrm{MgCl}$, 1 mM EDTA, 1 mM spermidine, 1 mM PMSF, 1 mM DTT and 10\% glycerol. After filtering the homogenate through two layers of cheesecloth, the nuclei were pelleted by centrifugation at 72,000 $\mathrm{x}$ g in a SW 28 rotor (Beckman L7- 55) for $30 \mathrm{~min}$ at $4^{\circ} \mathrm{C}$. The pelleted nuclei were resuspended in lysis buffer (10 mM HEPES pH 7.6, $100 \mathrm{mM} \mathrm{KCl,} 3 \mathrm{mM} \mathrm{MgCl}_{2}, 0.1 \mathrm{mM}$ EDTA, $1 \mathrm{mM}$ DTT, $0.1 \mathrm{mM}$ PMSF, 10\% glycerol). To precipitate the chromatin, $\left(\mathrm{NH}_{4}\right)_{2} \mathrm{SO}_{4} \mathrm{pH} 7.9$ was added slowly with constant stirring to a final concentration of $0.36 \mathrm{M}$. Chromatin was sedimented by centrifugation $(82,000 \mathrm{x} \mathrm{g}$, Beckman Ti 50 rotor, $60 \mathrm{~min}, 4^{\circ} \mathrm{C}$ ). The nucleoproteins were precipitated from the supernatant after the addition of crystallized $\left(\mathrm{NH}_{4}\right)_{2} \mathrm{SO}_{4}$ to a final concentration of $2.6 \mathrm{M}$ and sedimented by centrifugation at $82,000 \mathrm{x} \mathrm{g}$ in a Ti 50 rotor for $30 \mathrm{~min}$ at $4^{\circ} \mathrm{C}$. Nuclear extracts were dialyzed overnight against $25 \mathrm{mM} \mathrm{Hepes} \mathrm{pH} 7.6,40 \mathrm{mM} \mathrm{KCl}, 0.1 \mathrm{mM}$ EDTA, $1 \mathrm{mM}$ DTT and $10 \%$ glycerol, resuspended in dialysis buffer and frozen in small aliquots at $-80^{\circ} \mathrm{C}$.

\section{SDS-PAGE and immunoblot analysis}

For SDS-polyacrylamide gel electrophoresis (SDS-PAGE) $20 \mu$ g of proteins were loaded onto $4 \%$ stacking $12 \%$ separating gels. Nucleoproteins separated by SDS-PAGE were transferred to PVDF membranes (HybondP, Amersham Pharmacia Biotech) and Western immunoblot analysis was performed. Immunoblot analysis was performed using antibodies purchased from Santa Cruz Biotechnology: rabbit polyclonal antibodies for Akt 1/2/3 (H-136), pAkt 1/2/3 (ser 473)-R, p38 (C-20), p-p38 (Tyr 182)-R, ERK1 (K-23), pERK-1/2 (Thr 202-Tyr 204), JAK1 (H-106), NFKB p65 (C-20), pNFkBp65 (Ser 311), STAT3 (H-190), pSTAT3 (Tyr 705)$\mathrm{R}, \beta$ actin (C-11)-R, goat polyclonal antibodies for pJNK (Thr 183/Tyr 185), pJAK1 (Tyr 1022/Tyr 1023), NF- $\mathrm{kB}$ (p50) (D17) and mouse monoclonal antibody JNK (F-3). The blots were probed with horseradish peroxidase-conjugated goat anti-rabbit IgG and/or bovine anti-goat IgG (Santa Cruz Biotechnology). Staining was performed by the chemiluminescent technique according to the manufacturer's instructions (Santa Cruz Biotechnology). 
Determination of plasma superoxide anion radical $\left(\mathrm{O}_{2}^{-}\right)$and hydrogen peroxide $\left(\mathrm{H}_{2} \mathrm{O}_{2}\right)$ concentrations

The nitroblue tetrazolium reduction assay was used to measure the level of $\mathrm{O}_{2}{ }_{2}^{-}[15]$. The concentration of $\mathrm{H}_{2} \mathrm{O}_{2}$ was loaded with the appropriate standard curves for $\mathrm{H}_{2} \mathrm{O}_{2}$, and expressed in $\mathrm{nmol} / \mathrm{ml}$ of liver cells [16].

Determination of superoxide dismutase (SOD), catalase (CAT) and glutatione S transferase (GST) activity in liver

Total liver was homogenized in 0.25 M sucrose, 0.1 M EDTA and 0.05 M Tris-HCl, pH 7.4. After sonication the homogenate was centrifuged for $90 \mathrm{~min}$ at $100000 \mathrm{x}$ g. Aliquots of the supernatant were stored at $-80^{\circ} \mathrm{C}$. Total SOD activity was measured using the epinephrine method [17]. Mn-SOD activity was performed after preincubation with $8 \mathrm{mmol} / \mathrm{L} \mathrm{KCN}$ while CuZnSOD activity was calculated from the difference between total SOD and MnSOD activities. CAT activity was measured by the rate of hydrogen peroxide decomposition [18]. GST activity was determined by the method based on the reaction of 1-chloro-2,4-dinitrobenzene (CDNB) with -SH groups of glutathione catalyzed by GST contained in the samples [19].

\section{TBARS assay}

TBARS assay is based on the reaction of malondialdehyde (MDA) with thiobarbituric acid (TBA) at $95^{\circ} \mathrm{C}$. The level of TBARS was determined according to the method of Ohkawa et al. [20]. A calibration curve was prepared with an MDA standard (MDA concentrations ranged from $25 \mathrm{nmol} / \mathrm{ml}$ to $1 \mu \mathrm{mol} / \mathrm{ml}$ ).

\section{Comet assay}

Hepatocytes were assayed for DNA damage using the comet assay as described by modificated method of Singh [21]. The suspension of isolated hepatocytes, from control and diabetic rats and $0.5 \%$ low-melting agarose (Sigma) were overlaid onto the precoated slides. Lysis of the cells, under high salt concentration is then carried out to remove cellular proteins and liberate the damaged DNA. This liberated DNA is subjected to unwinding under alkaline to allow DNA supercoils to relax and express DNA single strand breaks and alkali labile sites. The slides were transferred to an electrophoresis tank with fresh alkaline electrophoresis buffer and separated at $1.33 \mathrm{~V} / \mathrm{cm} ; 0.01 \mathrm{kV}-139 \mathrm{~mA}$ for $20-30 \mathrm{~min}\left(4^{\circ} \mathrm{C}\right)$. After neutralization in $0.4 \mathrm{M}$ Tris$\mathrm{HCl}$ (pH 7.4) for $15 \mathrm{~min}$, the slides were stained with $100 \mu \mathrm{l}$ SYBR Green I (Sigma) and examined for DNA damage using a fluorescent microscope (Leica DM LB, filter fluorescent emission at $520 \mathrm{~nm}$ ). All steps were conducted under yellow light or in the dark to prevent nonspecific DNA damage by the Olive moment. Olive Tail Moment is defined as the product of the tail length and the fraction of total DNA in the tail. Tail moment incorporates a measure of both the smallest detectable size of migrating DNA (reflected in the comet tail length) and the number of relaxed/broken pieces (represented by the intensity of DNA in the tail). At least one hundred cells per sample were analyzed and DNA damage was quantified. 50-100 cells are counted per sample, by manual counting or using software. Both qualitative and quantitative assessment of DNA damage was carried out.

\section{Statistical analysis}

The results were analyzed by one-way ANOVA followed by the Mann-Whitney U-test (post-hoc comparison was performed between intact control and treated groups). The results were considered to be statistically significant at $\mathrm{p}<0.05$.

\section{Results}

Diabetes related DNA damage in the liver

To evaluate the level of DNA damage in the liver of STZ treated rats in the development stage (two weeks of diabetes induction) and stable diabetes (eight weeks of diabetes induction), we analyzed categories of comets (Fig. 1 A, B) and Olive moment (1 C). DNA damage was significantly increased in the development stage (Fig. $1 \mathrm{~A}-\mathrm{b}$ ) of diabetes compared to the control (Fig. $1 \mathrm{~A}-\mathrm{a}$ ) and rats with stable diabetes, (Fig. $1 \mathrm{~A}-\mathrm{c}$ ). Control had the highest number of undamaged cells. In addition, other categories of comets were almost completely absent (Fig. 1 B). During the development stage of diabetes, significant cell damage (28 fold 


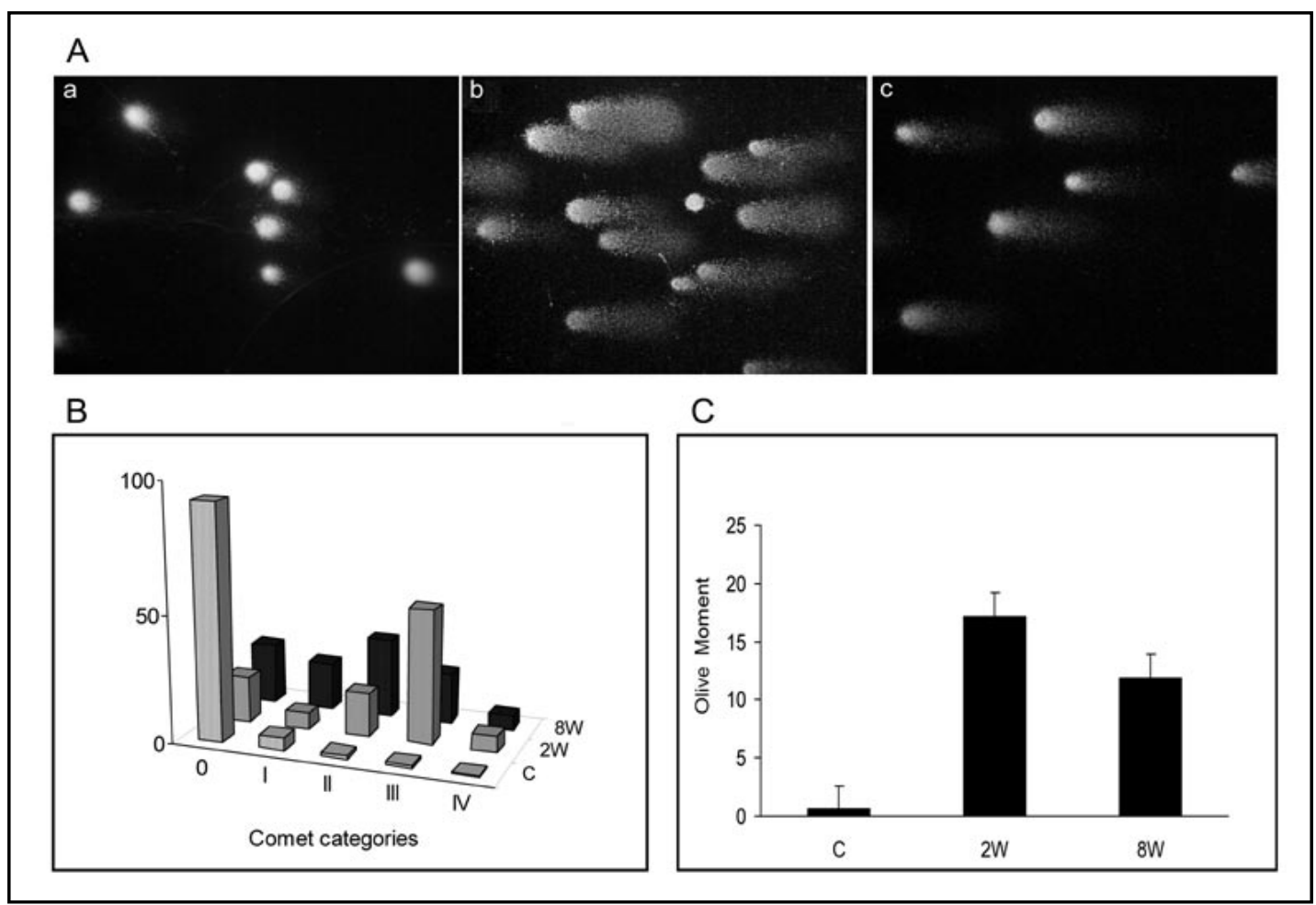

Fig. 1. DNA damage during the development stage and stable diabetes. A. Comet assay images: untreated hepatocyte (a), hepatocyte of the development stage $(2 \mathrm{~W} ; \mathrm{b})$ and hepatocyte of stable (8W; c) diabetes. All analyzed diabetic hepatocytes have significantly higher number of comet tails indicating DNA damage in comparison with control $(\mathrm{p}<0.001)$. B. Comet categories. Untreated and diabetic liver cell samples were used for visual scoring of about 100 comets and were classified in categories 0 -4. Categorization of comets from 0 to 4 expresses the level of cell damage during the development stage (2W) and stable diabetes (8W). C. Olive moment. The percentage of damaged cells in each experimental group was expressed by Olive moment, using comet score program.

compared to control) was observed, with prevailing comet II and III categories (Fig. 1 B, C). In $8^{\text {th }}$ week, when stable diabetes was established, we registered lower rate of damage than in the $2^{\text {nd }}$ week ( 0.6 fold compared to the development stage). However, it was far higher (19 fold) than in the control, detected by Olive moment and the damage included all types (I to IV) of comet categories (Fig. 1 B, C).

Oxidative status during the development stage and stable diabetes

We analyzed changes in the concentrations of $\mathrm{O}_{2}^{-}$and $\mathrm{H}_{2} \mathrm{O}_{2}$ during the progression of diabetes. Measuring the $\mathrm{O}_{2}^{-}$level in the plasma of diabetic rats showed almost linear increase starting from the $2^{\text {nd }}$, until the $8^{\text {th }}$ week after STZ induction (Fig. $2 \mathrm{~A}$ ). We observed that concentration of $\mathrm{H}_{2} \mathrm{O}_{2}$ was significantly increased in the development stage of diabetes, when it reached its maximum value (2.8 fold than in the controls). In stable diabetes, the concentration of $\mathrm{H}_{2} \mathrm{O}_{2}$ decreased but remained increased compared to control samples (Fig. 2 A).

In order to confirm the presence of oxidative stress in diabetic liver we analyzed changes in the level of lipid peroxides by TBARS assay. As seen in Fig. 2 B, the level of lipid peroxides was significantly higher in both the development stage and stable diabetes (Fig. 2 B) compared to the respective control groups. 
Fig. 2. Changes in oxidative status during diabetes. A. Plasma concentration of superoxide anions $\left(\mathrm{O}_{2}^{-}\right)$and hydrogen peroxide $\left(\mathrm{H}_{2} \mathrm{O}_{2}\right)$ in development stage (2W) and stable diabetes $(8 \mathrm{~W}) \mathrm{B}$. The level of malondialdehyd (MDA) in the liver. C. MnSOD, CAT and GST activity in the liver. Shown values represent \pm SD from five separate experiments. The minimum level of significance was ${ }^{*} \mathrm{p}<0.05$.

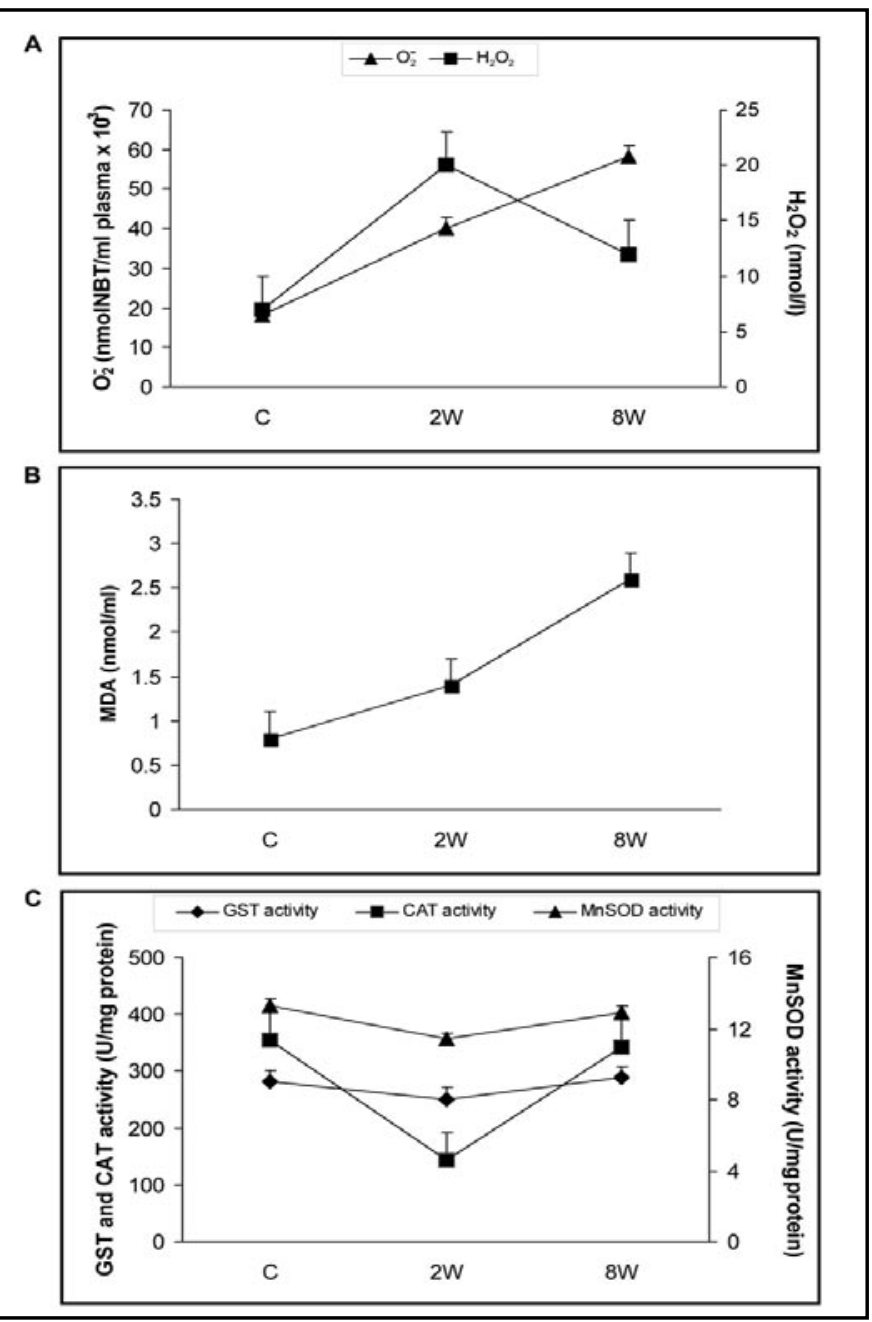

In the development stage of diabetes (Fig. 2 C), activity of MnSOD, CAT and GST in the liver was significantly lower (about $0.3,0.6$ and 0.28 fold, respectively) compared to control (Fig. 2 C). Their activity returned to the control values (Fig. 2 C) in the stable diabetes. We noticed a decline of activity in the development stage of diabetes among all analyzed enzymes but most extensively in catalase activity which was associated with a significant increase in $\mathrm{H}_{2} \mathrm{O}_{2}$ concentration.

Diabetes-activated signaling pathways in the liver

In order to investigate the activity of TNF $\alpha$ induced signaling pathways in the liver of diabetic rats, diabetes-related temporal changes in serum concentration of TNF $\alpha$ was investigated first. Concentration of TNF $\alpha$ was elevated by almost 9 fold in the development stage of diabetes and by about 4 fold in stable diabetes, compared to control (Fig. $3 \mathrm{~A}$ ).

Immunoblot analysis of the liver homogenates with anti-Akt and p-Akt antibodies revealed two isoforms $(60 / 56 \mathrm{kDa})$ in the control and diabetic hepatocytes (Fig. $3 \mathrm{~B}, \mathrm{C})$. In diabetic rats, only the level of $60 \mathrm{kDa}$ isoform progressively increased with time and had maximal expression (about 2 fold) in stable diabetes. Densitometry analysis of p-Akt isoforms has not shown a significant increase in the development stage of diabetes. However, stable diabetes is accompanied by a significant increase in both 60 and $56 \mathrm{kDa}$ isoforms for 3 and 2.7 fold respectively, compared to control. These results indicated activation of Akt signaling pathway in stable diabetes rather than in the development stage. 
A

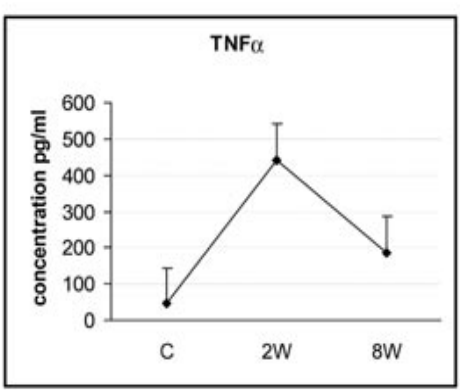

B

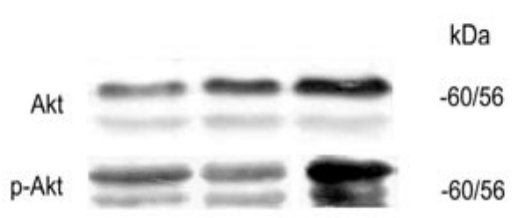

C
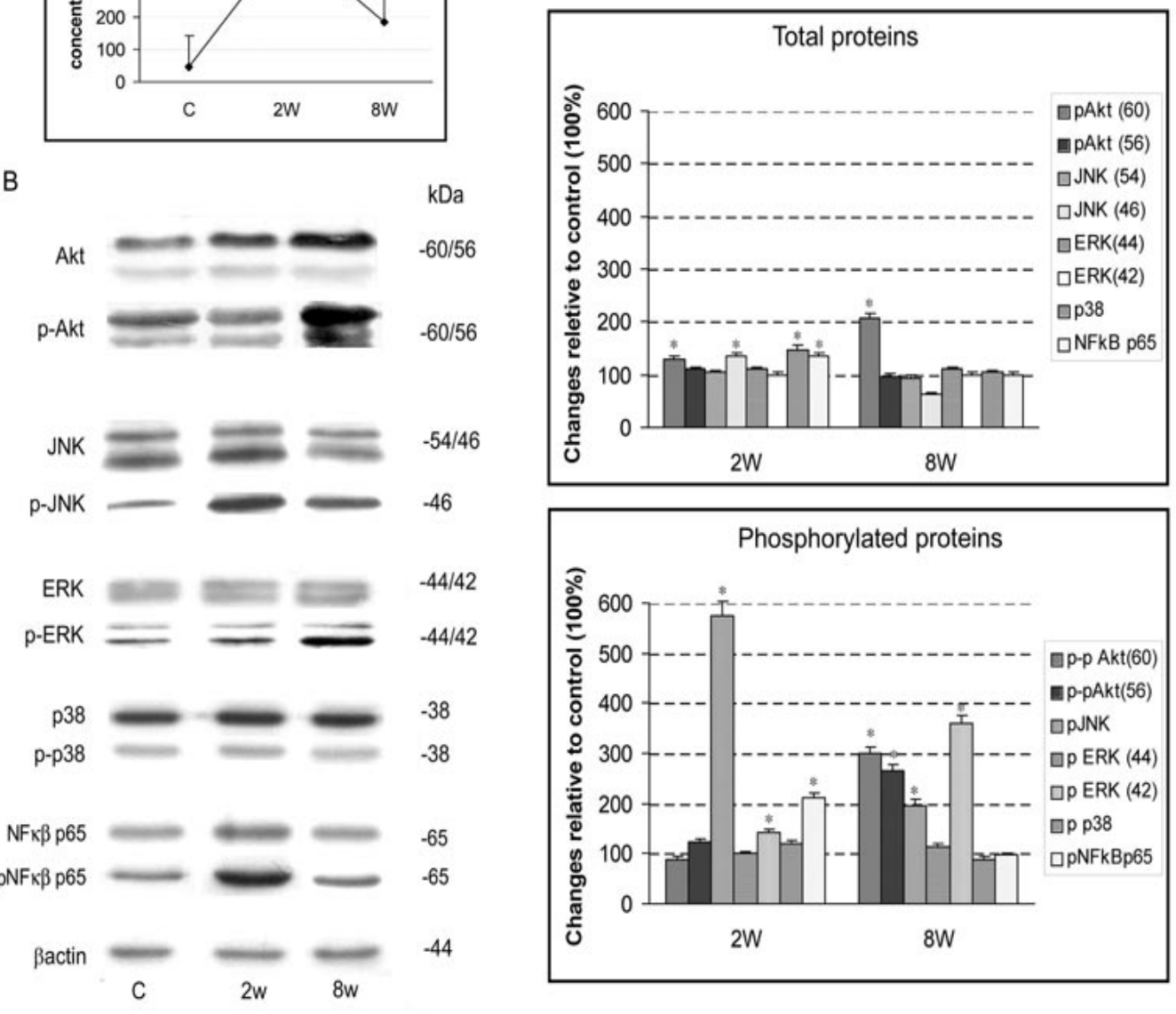

Fig. 3. Activation of TNF $\alpha$ related signaling pathways in the liver during diabetes. A. Serum concentration of TNF $\alpha$. B. Representative Western blots of proteins from control liver homogenates and homogenates in the development stage (2W) and stable diabetes ( $8 \mathrm{~W}) ; \beta$-actin was used as a loading control. C. Densitometric analysis of individual bands of total proteins and phosphorylated forms are compared to control level $(100 \%)$. Values are means \pm SD from 10 animals. ${ }^{*} \mathrm{p}<0.05$ significantly different from control animals.

Immunoblot analysis of liver homogenates in the development stage and stable diabetes with polyclonal antibodies to MAP kinase (p38, JNK and ERK) as well as detection of their phosphorylated form with the polyclonal antibodies against p-p38, $\mathrm{p}$-JNK and p-ERK were presented on Fig. 3 B and C. In comparison with control samples we detected increased expression only of the $46 \mathrm{kDa}$ JNK isoform (1.3 fold) in the development stage of diabetes which was followed by its increased phosphorylation ( 6 fold). In stable diabetes total expression of $46 \mathrm{kDa}$ JNK isoform as well as its activation by phosphorylation significantly decreased. These results implicated activation of JNK signaling pathway in the development stage of diabetes and reduction of its activation in stable diabetes. Immunoblot analysis detected two isoforms of ERK $(42 / 44 \mathrm{kDa})$ in liver homogenates from control and diabetic rats. No changes were detected in expression levels of these isoforms during diabetes progression. However we detected increase in phosphorylation of $42 \mathrm{kDa}$ isoform which 


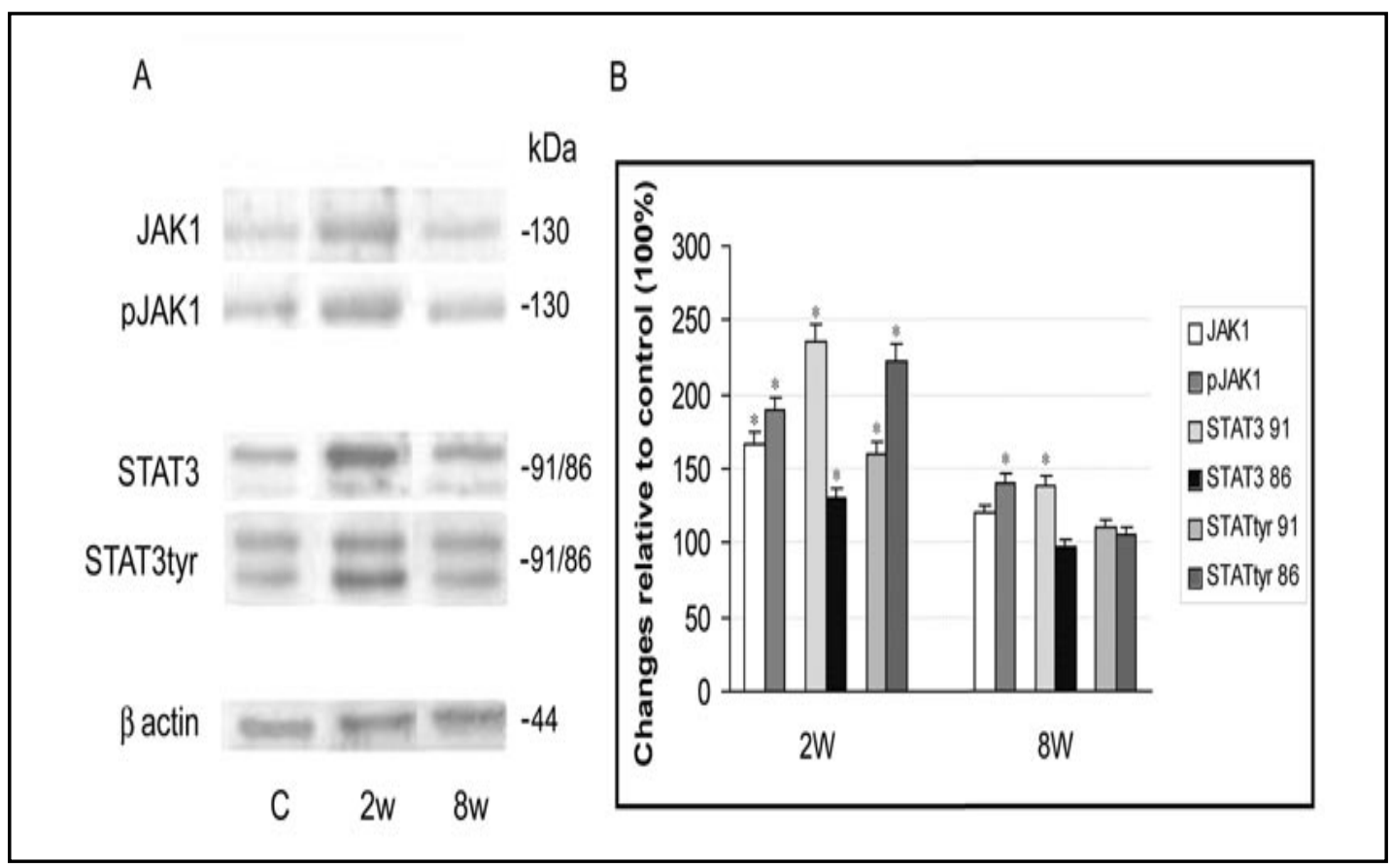

Fig. 4. Activation of JAK/STAT signaling pathway in the liver during diabetes. A. Western blot analyzes of rat liver homogenates from control and diabetic rats in development phase (2W) and stable stage (8W); $\beta$-actin was used as a loading control. B. Densitometric analyses of individual bands of total proteins and phosphorylated forms. Values are means \pm SD from 10 animals. ${ }^{*} \mathrm{p}<0.05$ significantly different from control animals.*

was 1.7 fold in the development stage and 3.2 fold in stable diabetes. Significant increase in phosphorylation of $42 \mathrm{kDa}$ isoform of ERK in stable diabetes followed by lower activity of 46 $\mathrm{kDa}$ JNK indicated activation of ERK signal pathway in stable diabetes and silencing of JNK signaling pathway. Increase in total expression of p38 was detected only in the development stage and it had no significant changes in its activation by phosphorylation.

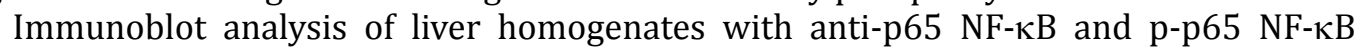
antibodies was presented in Fig. $3 \mathrm{~B}$ and C. In comparison with control samples we detected increased expression of p $65 \mathrm{NF \kappa B}$ (1.4 fold) only in the development stage of diabetes which was followed by its increased phosphorylation ( 2.2 fold).

Immunoblot analyses of liver homogenates with polyclonal antibodies against JAK1 and STAT3 are presented on Fig. 4 A and B. Increased expression and activity of JAK1 in the development stage were followed by increased expression and activity of STAT3 proteins. Expression of $91 \mathrm{kDa}$ STAT3 isoform increased about 2.4 fold compared to control, while $86 \mathrm{kDa}$ STAT3 increased 1.3 fold. Additionally activity of these isoforms increased about 1.7 and 3.5 fold, respectively. Decreased expression and activity of JAK1 in stable diabetes was followed by a similar decrease of STAT3 expression and activity. These results indicate that JAK1/STAT signaling pathway is mostly active in developing stage of diabetes.

\section{Discussion}

Presented study was designed to investigate liver response specificity to oxidative stress conditions caused by diabetes in its development and stable phases, with special attention to the relations between the level of DNA damage in hepatocytes and activity of stress sensitive signal transduction pathways which can determine whether the cell will die or survive in the existing conditions. 
We detected high levels of $\mathrm{O}_{2}^{-}$and $\mathrm{H}_{2} \mathrm{O}_{2}$ which can perturb the normal redox balance and shift cells into a state of oxidative stress in both development stage and stable diabetes (Fig. 2 A). In order to prevent oxidative related tissue damage the cell activates antioxidant enzymes whose efficiency varies in different tissues depending on monitored stage of diabetes. In literature, diabetes was associated with significantly increased activities of CAT and SOD in the pancreas; on the other hand, the liver of diabetic rats showed generalized decrease or increase in CAT and SOD activity [22-24]. In our study, elevated level of ROS, especially $\mathrm{H}_{2} \mathrm{O}_{2}$, was accompanied by reduced activity of CAT, GST and MnSOD during the development stage of diabetes. Antioxidative protection returns to control level in stable diabetes, despite high levels of $\mathrm{O}_{2}{ }^{-}$and $\mathrm{H}_{2} \mathrm{O}_{2}$. Balance between ROS and enzymatic activity status reflects in different degrees of hepatocyte damage, during both stages of diabetes. Comet assay analysis points that diabetes leads to significant DNA damage in the liver. According to Olive moment, DNA damage was most prominent in the development phase when 28 fold increase was detected. The level of DNA damage in stable diabetes was lower (19 fold). The amount of DNA breaks depends on different factors. Our findings support the view that the tissue antioxidant status may be an important factor in the etiology of diabetes and its complications, even though DNA damage can be repaired by various mechanisms. If the induced damage is greater than the repair capacity, then the amount of DNA breaks increases and it may finally contribute to the development of illness. The greatest cell damage, detected during the the development stage of diabetes, correlated with the highest level of $\mathrm{H}_{2} \mathrm{O}_{2}$ and reduced level of CAT activity. Cell damage in stable diabetes decreases, comparing to the development stage. At the same time CAT activity approaches control values and the concentration of $\mathrm{H}_{2} \mathrm{O}_{2}$ decreases. Lower damage of hepatocytes in stable diabetes and improved oxidative status, compared to the development stage, indicated possible adaptation of liver cells to oxidative stress. That could be related to preconditioning, situation in which the activated state of the cell provides temporary benefit in protection from other damaging agents $[25,26]$.

Although ROS are shown to play an important role in the pathogenesis of human diseases such as diabetes, they can no longer be regarded solely as damaging species. Beneficial effects of ROS occur at low/moderate concentrations and involve physiological role in cellular responses to oxidative stress [2]. In fact, some ROS-mediated actions protect cells against ROS-induced oxidative stress and re-establish or maintain "redox balance". The "two-faced" character of ROS is clearly substantiated. Growing body of evidence shows that within cells ROS act as secondary messengers in intracellular signaling cascades and have role in redox regulation of normal physiological functions, as well as in pathophysiological implications of altered redox regulation in diseases [7]. Increased ROS are able to activate specific signaling pathways which may lead to cell death or cell survival. Thus, differences in hepatocytes' response during the development stage and stable diabetes could be also related to the activation of different signaling pathways which leads either to survival or to cell death.

The proinflammatory cytokine $\mathrm{TNF} \alpha$ is a key regulator of vital balance between hepatocyte's survival and death; hence, it can induce hepatocyte proliferation as well as cell death [27]. The mechanisms by which ROS regulate TNFo-induced hepatocyte death are complex and not fully understood but mitochondrial ROS might contribute to apoptosis by promoting peroxidation [28]. The development stage of diabetes characterize large presence of peroxide and lipid peroxidation as well as significant rise of TNF $\alpha$ concentration, while stable diabetes is accompanied by a decrease in the concentration of peroxide, TNF $\alpha$ activity, and persistent high lipid peroxidation (Fig. 2, 3 A). Although TNF $\alpha$ can contribute to hepatocyte cell death during liver diseases, healthy liver has well-developed defense mechanisms that permit adaptation of hepatocytes to TNF $\alpha$-initiated stress. TNF $\alpha$ can initiate signal pathways leading to the activation of the NF- $\kappa B$, and the initiation of MAPK cascades. Multiple studies have shown that TNF-induced JNK activation determine the biological outcome of TNF $\alpha$ stimulation. While transient and modest activation of JNK is associated with cellular survival, prolonged and robust activation of JNK plays an important role in TNF-induced cell death $[12,29,30]$. Moreover, level of TNF $\alpha$ induced JNK activation 
seems to be controlled by NF- $\kappa B$ activation [29-31]. Recent studies have indicated that one of the antiapoptotic functions of NF- $\kappa \mathrm{B}$ is to downregulate JNK activation through induction of MnSOD which combined restrain accumulation of ROS [29, 32]. In the absence of MnSOD in NF- $\mathrm{KB}$-deficient cells, phosphatases that activate MAP kinases are inhibited which results in prolonged JNK activation [33, 34].

The fact that NF- $\kappa B$ and JNK signal pathways are activated at the same time in the development stage of diabetes, seems to be contradictory because according to current knowledge, elevated NF- $\mathrm{BB}$ should cause a blockade of JNK signaling pathway [29]. It is assumed that the NF- $\kappa B$ blockade is achieved through high levels of MnSOD, thus contributing to cell survival $[33,35]$. Decreased level of MnSOD, CAT and GST activity in the development stage of diabetes indicated that high level of NF- $\kappa B$ is not sufficient to suppress JNK signaling pathway at this stage. Activated JNK signaling pathway leads to cell death, which we registered as a DNA damage in hepatocytes (Fig. 1). In the other hand, biochemical analysis indicates that under non-stressed conditions GST binds to JNK and inhibits its activation but this interaction is disrupted by oxidative stress [8]. Several studies have provided evidence that JNK activation by $\mathrm{H}_{2} \mathrm{O}_{2}$ and/or stresses that affect the cellular redox state occurs partially through suppression of phosphatases involved in JNK inactivation [34, 35].

Most studies seem consistent with the notion of relationship of JNK signaling with ERK and the Akt pathways [36,37]. Both pathways ERK and the Akt are prosurvival and are activated in stable diabetes but not in the development stage. Minor damage of hepatocytes in stable diabetes correlated with finding that a rapid activation of P44/42 ERK participates in the preservation of liver cells [38]. Hence, it was suggested that the balance between magnitude of ERK and JNK activation was the key to determining survival or death of the cells [39]. In the development stage of diabetes activation of JNK pathway is prevalent, without the activation of ERK which contributes to cell death in hepatocytes. In stable diabetes TNF $\alpha$ is slightly elevated, NF- $\mathrm{KB}$ is not activated, JNK is suppressed, ERK and the Akt pathways are activated and all tested enzymes of oxidative stress are on the control level. Our results suggest that the development stage of diabetes led to activation of JAK/STAT pathway in the liver, which correlated with the literature data stating that preconditioning with $\mathrm{H}_{2} \mathrm{O}_{2}$ activated the JAK-STAT and MAPKs pathways in cell culture [40]. In diabetic liver STAT3 was phosphorylated, indicating the activation of pro-survival signaling [40].

In summary, the development stage of diabetes, which is accompanied by extensive DNA damage in hepatocytes, is characterized by activation of NF- $\kappa B$, JAK-STAT and JNK signaling pathways whose balance is acting mostly proapoptotically. Recognition of JNK signaling as a critical promoter of hepatocyte death raises the possibility of therapeutic manipulation of this pathway. This might be important to find an efficient treatment for the development stage of diabetes. In stable diabetes, Akt and ERK signaling pathways are activated, contributing to survival and recovery of hepatocytes. Activation of these pathways could also contribute to preconditioning and prevention of additional stress in stable diabetes.

\section{Conflict of interest}

The authors have no conflict of interest to declare.

\section{Abbreviations}

CAT (Catalase); ERK (Extracellular Receptor Kinase); GST (Glutatione S Transferase); JAK (Janus Kinase); JNK (Jun N-terminal Kinase); MnSOD (Mangan Superoxide Dismutase); NFкB (Nuclear Faktor Kappa B); SOD (Superoxide Dismutase); p38 (Mitogen-Activated Protein Kinase); STAT3 (Signal Transducer and Activator of Transcription 3); STZ (Streptozotocin); TNF $\alpha$ (Tumor Necrosis Faktor $\alpha$ ). 
Martinović/Grigorov/Bogojević et al.: Signaling Pathways in Diabetic Liver

\section{Acknowledgements}

This work was supported by the Ministry of Education and Science, Republic of Serbia, grant 173020.

\section{References}

1 Maritim AC, Sanders RA, Watkins JB: Diabetes, oxidative stress, and antioxidants: a review. J Biochem Mol Toxicol 2003;17:24-38.

-2 Martindale JL, Holbrook NJ: Cellular response to oxidative stress: signaling for suicide and survival. J Cell Physiol 2002;192:1-15.

3 Kahn SE: The relative contributions of insulin resistance and $\beta$-cell dysfunction to the pathophysiology of Type 2 diabetes. Diabetologia 2003;46:3-19.

$\checkmark 4$ Kajimoto Y, Kaneto H: Role of oxidative stress in pancreatic $\beta$-cell dysfunction. Ann N Y Acad Sci 2004;1011:168-176.

5 Newsholme P, Haber EP, Hirabara SM, Rebelato EL, Procopio J, Morgan D, Oliveira-Emilio HC, Carpinelli AR, Curi R: Diabetes associated cell stress and dysfunction: role of mitochondrial and non-mitochondrial ROS production and activity. J Physiol 2007;583:9-24.

6 Evans JL, Goldfine ID, Maddux BA, Grodsky GM: Oxidative Stress and Stress-Activated Signaling Pathways: A Unifying Hypothesis of Type 2 Diabetes. Endocr Rev 2002;23:599-622.

7 Valko M, Leibfritz D, Moncola J, Cronin M, Mazura M, Talser J: Free radicals and antioxidants in normal psysiological functions and human disease. Int J Biochem Cell Biol 2007;39:44-84.

$>8$ Finkel T, Holbrook NJ: Oxidants, oxidative stress and the biology of ageing. Nature 2000;408;239-246. Baynes JW: Role of oxidative stress in development of complications in diabetes. Diabetes 1991;40:405412.

10 Yamamoto K, Tsukidate K, Farber JL: Differing effects of the inhibition of poly(ADP-ribose) polymerase on the course of oxidative cell injury in hepatocytes and fibroblasts. Biochem Pharmacol 1993;46:483-491.

11 Fabregat I, Roncero C, Fernandez M: Survival and apoptosis: a dysregulated balance in liver cancer. Liver Int 2007;27:155-162.

-12 Nakano H, Nakajima A, Sakon-Komazawa S, Piao J-H , Xue X, Okumura K: Reactive oxygen species mediate crosstalk between NF- $\kappa B$ and JNK. Cell Death Differ 2006;13:730-737.

13 Ohno T, Horio F, Tanaka S, Terada M, Namikawa T, Kitch J: Fatty liver and hyperlipidemia in IDDM (insulin dependent diabetes mellitus) of Streptozotocin treated shrews. Life Sci 2000;66:125-131.

14 Merzouk H, Madani S, Chabane SD, Prost J, Bouchenak M, Belleville J: Time course of changes in serum glucose, insulin, lipids and tissue lipase activities in macrosomic offspring of rats with Streptozotocin induced diabetes. Clin Sci 2000;98:21-30.

15 Auclair C, Voisin E: Nitroblue tetrazolium reduction; in Greenwald RA (ed): Handbook of Methods for Oxygen Radical Research. , CRC Press, Boca Raton, 1985, pp 123-132.

16 Pick E, Keisari Y: A simple colorimetric method for the measurement of hydrogen peroxide produced by cells in culture. J Immunol Meth 1980;38:161-170.

$\checkmark 17$ Misra HP, Fridovich I: The role of superoxide anion in the autoxidation of epinephrine and simple assay for superoxide dismutase. J Biol Chem 1972;247:3170-3175.

18 Beutler E: Glutathione; in Beutler E (ed): Red Cell Metabolism, a Manual of Biochemical Methods., New York, Grune and Stratton, 1975, pp 112-114.

19 Habig WH, Pabst MJ, Jakoby WB: Glutathione S-transferase. J Biol Chem 1974;249:7130-7139.

20 Ohkawa H, Ohishi N, Yagi K: Assay for lipid peroxides in animal tissues by thiobarbituric acid reaction. Anal Biochem 1979;95:351-358.

-21 Singh NP, McCoy MT, Tice RR, Schneider EL: A simple technique for quantitation of low levels of DNA damage in individual cells. Exp Cell Res 1988;175:184-191.

22 Wohaieb SA, Godin DV: Alterations in free radical tissue-defense mechanisms in streptozocin-induced diabetes in rat. Effects of insulin treatment. Diabetes 1987;36:1014-1018.

23 Kakkar R, Mantha SV, Radhi J, Prasad K, Kalra J: Increased oxidative stress in rat liver and pancreas during progression of streptozotocin-induced diabetes. Clin Sci 1998;94:623-632. 
Martinović/Grigorov/Bogojević et al.: Signaling Pathways in Diabetic Liver

24 Szaleczky E, Prechl J, Fehér J, Somogyi A: Alterations in enzymatic antioxidant defence in diabetes mellitus - a rational approach. Postgrad Med J 1999;75:13-17.

25 Kremastinos DT: The Phenomenon of Preconditioning Today. Hellenic J Cardiol 2005;46:1-4.

-26 Teoh N, Leclercq I, Pena AD, Farrell G: Low dose TNF-alpha protects against hepatic ischemia-reperfusion injury in mice: implications for preconditioning. Hepatology 2003;37:118-128.

-27 Evans JL, Goldfine ID, Maddux BA, Grodsky GM: Are oxidative stress-activated signaling pathways mediators of insulin resistance and $\beta$-cell dysfunction. Diabetes 2003;52:1-8.

-28 Wullaert A, van Loo G, Heyninck K, Beyaert R: Hepatic tumor necrosis factor signaling and nuclear factor- $\mathrm{\kappa B}$ : effects on liver homeostasis and beyond. Endocr Rev 2007;28:365-386.

29 Bubici C, Papa S, Pham CG, Zazzeroni F, Franzoso G: The NF- $\kappa B$-mediated control of ROS and JNK signaling. Histol Histopathol 2006;21:69-80.

30 Papa S, Bubici C, Zazzeroni F, Franzoso G: Mechanisms of liver disease: the crosstalk between the NF- $\kappa B$ and JNK pathways. Biol Chem 2009;390:965-976.

-31 Roberts RA, James NH, Cosulich SC: The Role of Protein Kinase B and Mitogen-Activated Protein Kinase in Epidermal Growth Factor and Tumor Necrosis Factor a-Mediated Rat Hepatocyte Survival and Apoptosis. Hepatology 2000;31:420-427.

-32 Bernard D, Quatannens B, Begue A, Vandenbunder B, Abbadie C: Antiproliferative and antiapoptotic effects of crel may occur within the same cells via the up-regulation of manganese superoxide dismutase. Cancer Res 2001;61:2656-2664.

33 Kracht M: Targeting strategies to modulate the NF- $\mathrm{KB}$ and JNK signal transduction network. Antiinflamm Antiallergy Agents Med Chem 2007;6:71-84.

-34 Czaja MJ: The Future of GI and Liver Research: Editorial Perspectives III. JNK/AP-1 regulation of hepatocyte death. Am J Physiol Gastrointest Liver Physiol 2003;284:875-879.

35 Conde de la Rosa L, Schoemaker MH, Vrenken TE, Buist-Homan M, Havinga R, Jansen PL, Moshage H: Superoxide anions and hydrogen peroxide induce hepatocyte death by different mechanisms: involvement of JNK and ERK MAP kinases. J Hepatol 2006;44:918-929.

36 Davis RJ: Signal transduction by the JNK group of MAP kinases: Cell 2000;103:239-252.

-37 Hers I, Vincent EE, Tavaré JM: Akt signalling in health and disease. Cell Signal 2011;23:1515-1527.

38 Gao Y, Shan YQ, Pan MX, Wang Y, Tang LJ, Li H, Zhang Z: Protein kinase C-dependent activation of P44/42 mitogen-activated protein kinase and heat shock protein 70 in signal transduction during hepatocyte ischemic preconditioning. World J Gastroenterol 2004;10:1019-1027.

-39 Xia Z, Dickens M, Raingeaud J, Davis RJ, Greenberg ME: Opposing Effects of ERK and JNK-p38 MAP Kinases on Apoptosis. Science 1995;270:1326-1331.

40 Yu HM, Zhi JL, Cui Y, Tang EH, Sun SN, Feng JQ, Chen PX: Role of the JAK-STAT pathway in protection of hydrogen peroxide preconditioning against apoptosis induced by oxidative stress in PC12 cells. Apoptosis 2006;11:931-941. 